\title{
Helicobacter pylori Infection and Its Risk Factors: A Prospective Cross-Sectional Study in Resource-Limited Settings of Northwest Ethiopia
}

\author{
Markos Negash $\mathbb{D}^{1},{ }^{1}$ Habtamu Wondifraw Baynes $\mathbb{D},{ }^{2}$ and Demeke Geremew ${ }^{1}$ \\ ${ }^{1}$ Department of Immunology and Molecular Biology, School of Biomedical and Laboratory Sciences, \\ College of Medicine and Health Sciences, University of Gondar, Gondar, Ethiopia \\ ${ }^{2}$ Department of Clinical Chemistry, School of Biomedical and Laboratory Sciences, College of Medicine and Health Sciences, \\ University of Gondar, Gondar, Ethiopia
}

Correspondence should be addressed to Markos Negash; markosnegash@yahoo.com

Received 19 July 2018; Accepted 19 September 2018; Published 18 October 2018

Guest Editor: Teresa Fasciana

Copyright ( 2018 Markos Negash et al. This is an open access article distributed under the Creative Commons Attribution License, which permits unrestricted use, distribution, and reproduction in any medium, provided the original work is properly cited.

\begin{abstract}
Background. Helicobacter pylori (H. pylori) is implicated for the causation of gastrointestinal tract infections including gastric cancer. Although the infection is prevalent globally, the impact is immense in countries with poor environmental and socioeconomic status including Ethiopia. Epidemiological study on the magnitude of $H$. pylori and possible risk factors has priceless implication. Therefore, in this study, we determined the prevalence and risk factors of $H$. pylori infection in the resource-limited area of northwest Ethiopia. Methods. A prospective cross-sectional study was conducted on northwest Ethiopia among 201 systematically selected dyspeptic patients. Data were collected using a structured and pretested questionnaire, and stool and serum samples were collected and analyzed by SD BIOLINE $H$. pylori Ag and dBest $H$. pylori Disk tests, respectively. Chi-square test was performed to see association between variables, and binary and multinomial regression tests were performed to identify potential risk factors. $P$ values $<0.05$ were taken statistically significant. Result. Prevalence of $H$. pylori was found to be $71.1 \%(143 / 201)$ and $37.3 \%$ (75/201) using the dBest $H$. pylori Test Disk and SD BIOLINE H. pylori Ag test, respectively. H. pylori seropositivity, using $\mathrm{dBest} H$. pylori Disk tests, is significantly associated in age groups $<10$ years $(P=0.044)$ and married patients $(P=0.016)$. In those patients with $H$. pylori (a positive result with either the Ab or Ag test), drinking water from well sources had 2.23 times risk of getting $H$. pylori infection $(P=0.017)$, and drinking coffee $(1.51(0.79-2.96, P=0.025))$ and chat chewing $(1.78(1.02-3.46$, $P=0.008)$ are the common risk factors. Conclusion. The present study discovered considerable magnitude of H. pylori among the dyspeptic patients in the study area. H. pylori infection is frequent in individuals drinking water from well sources, and thus, poor sanitation and unhygienic water supply are contributing factors. Policies aiming at improving the socioeconomic status will reduce potential sources of infection, transmission, and ultimately the prevalence and incidence of $H$. pylori.
\end{abstract}

\section{Background}

Helicobacter pylori (H. pylori) was the first formally recognized bacterial carcinogen. It has been etiologically associated with gastritis, peptic ulcer disease, gastric adenocarcinoma, and primary gastric lymphoma $[1,2]$.

Helicobacter pylori (H. pylori) colonizes $70-90 \%$ of the population in developing countries, whereas it is around $50 \%$ in developed countries [3-5]. In developing countries, an early childhood acquisition of $H$. pylori (30-50\%) reaching over $90 \%$ during adulthood is the pattern of infection. Unless treated, colonization persists lifelong. $H$. pylori infection has been attributed to poor socioeconomic status, poor hygienic practice, and overcrowding condition $[6,7]$, a whole mark in developing countries.

The bacterium differs genetically, survives in harsh acidic gastric environment, and currently develops resistance for several antibiotics. Although epidemiological distribution of $H$. pylori varies globally, the magnitude of $H$. pylori has been shown to be $70.1 \%$ (Africa), 69.4\% (South America), 66.6\% 
(Western Asia), 34.3\% (Western Europe), and 37.1\% (North America) [8-10].

The prevalence of $H$. pylori in the Ethiopian dyspeptic patients is similarly high to other developing countries because most Ethiopian population live in households with low socioeconomic status and hygiene $[7,11,12]$. Magnitude of $H$. pylori among the outpatient department (based on a test kit detecting Immunoglobulin $\mathrm{G}$ (IgG) antibodies) at the University of Gondar Hospital (UOG Hospital) was ranged between $65.7 \%$ and $85.6 \%$ [13, 14]. Besides, it is a common reason to seek primary healthcare service and accounts for $10 \%$ of hospital admissions $[15,16]$.

All previous prevalence researches in the study area were conducted using IgG and/or IgM antibody rapid tests which have questionable performance in detecting acute infection and distinguishing active infection from previous exposure. Hence, the current study was conducted with an aim to determine the prevalence of $H$. pylori infection among the dyspeptic patients attending the UOG hospital in northwest Ethiopia, using stool antigen as well as serum antibodies technique and assessing potential risk factors.

\section{Methods}

2.1. Study Design, Period, and Area. This is a facility-based cross-sectional study which was conducted on patients with dyspepsia from February to March 2016 at the University of Gondar Hospital, Gondar, Ethiopia. The University of Gondar Hospital is one of the pioneer teaching hospitals in Ethiopia conducting community-based researches, providing teaching and diagnostic services for more than 5 million inhabitants.

2.2. Study Participants and Clinical Data Collection. After informed consent was taken from the dyspeptic patients, who visited the hospital outpatient department, suspected of H. pylori infection, all relevant clinical and sociodemographic data were collected using a structured and pretested questionnaire by trained data collectors.

2.3. Specimen Collection and Processing. Stool and blood specimens were collected from each patient for $H$. pylori antigen and antibody tests, respectively. The blood was centrifuged until serum is separated and stored in $-20^{\circ} \mathrm{C}$. The stool specimens were also stored in $-20^{\circ} \mathrm{C}$ until the tests were performed. For this study, we followed the methods of Negash et al. [17] which has been evaluated four H. pylori diagnostic tests in the study area.

2.3.1. SD Bioline H. pylori Ag Test (Standard Diagnostic, Inc., Korea). Principle: the SD BIOLINE H. pylori Ag rapid test kit result window has 2 precoated lines, "T" (Test Line) and "C" (Control Line). Both the Test Line and the Control Line in the result window are not visible before applying any samples. The " $\mathrm{T}$ " window coated with monoclonal anti- $H$. pylori will form a line after the addition of the stool specimen (if there is H. pylori antigen). The Control window is used for the procedural control, and a line should always appear if the test procedure is performed correctly, and the test reagents are working [17].

2.3.2. dBest H. pylori Test Disk (Ameritech Diagnostic Reagent Co., Ltd., Tongxiang, Zhejiang, China). Principle: this test contains a membrane strip, which is precoated with $H$. pylori capture antigen on the test band region. The $H$. pylori antigen-colloid gold conjugate and serum sample moves along the membrane chromatographically to the test region ( $\mathrm{T}$ ) and forms a visible line as the antigen-antibodyantigen gold particle complex forms. This test device has a letter of T and C as "Test Line" and "Control Line" on the surface of the case. Both the test line and control line in the result window are not visible before applying any samples. The control line is used for the procedural control. Control line should always appear if the test procedure is performed properly, and the test reagents of the control line are working [17].

2.4. Statistical Analysis. The data were cleaned and double entered on the excel spread sheet and transported to Statistical Package for Social Sciences (SPSS). The chi-square test was performed to see association between dependent and independent variables. Binary logistic regression and multinomial regression tests were performed to identify potential risk factors of $H$. pylori infection. $P$ value less than 0.05 were considered statistically significant.

\section{Result}

3.1. Demographic Characteristics. A total of 201 dyspeptic patients were included in the study, and serum and stool samples were analyzed by dBest $H$. pylori Test Disk and SD BIOLINE $H$. pylori Ag tests, respectively. The mean \pm SD (range) age of the participants was $29.5 \pm 14.85$ (7-85) years with a median of 23 years. The majority (140) of the study participants were male (69\%), study subjects from the urban area (141) accounted $70 \%$, and $69(34.3 \%)$ of the participants were married. Of 201 participants, 104 (51\%) were students, 38 (18.9\%) were farmers, and $23(11.4 \%)$ were house wives (Table 1). In this study, participants who were diagnosed as positive to the $H$. pylori stool antigen test were immediately commenced appropriate therapy.

3.2. Prevalence of H. pylori with respect to Sociodemography of Participants. Accordingly, the prevalence of $H$. pylori was found to be $71.1 \%(143 / 201)$ and $37.3 \%(75 / 201)$ using the dBest H. pylori Ab Test Disk (95\% CI: 64.2-77.6) and SD BIOLINE H. pylori Ag test (95\% CI: 30.3-44.3), respectively (Table 2). The highest prevalence of $H$. pylori infection was seen among the males than the females ( 98 vs 45 by Ab test and 79 vs 27 by Ag test), and H. pylori is more frequent in individuals living from the urban area than rural (101 vs 42 using the Ab test and 76 vs 30 using the Ag test), respectively. Regarding the occupational status, the students are the majority groups who come up positive for $H$. pylori (both in 
TABLE 1: Prevalence of $H$. pylori infection among the dyspeptic patients across sociodemographic characteristics at the University of Gondar Hospital Outpatient Department, $N=201$.

\begin{tabular}{|c|c|c|c|c|}
\hline \multicolumn{2}{|c|}{ Sociodemographic characteristics } & \multirow{2}{*}{$\begin{array}{l}\text { Positive for the } \mathrm{Ab} \text { test, } N(\%) \\
98(70)\end{array}$} & \multirow{2}{*}{$\begin{array}{c}\text { Positive for the Ag test, } N(\%) \\
79(56.7)\end{array}$} & \multirow{3}{*}{$\begin{array}{c}\text { Total, N(\%) } \\
140(69.7) \\
61(30.3)\end{array}$} \\
\hline & Male & & & \\
\hline Sex & Female & $45(73.8)$ & $27(44.3)$ & \\
\hline \multirow{7}{*}{ Age (years) } & $<10$ & $1(50)^{*}$ & $1(50)$ & $2(1)$ \\
\hline & $10-19$ & $10(55.6)$ & $12(66.7)$ & $18(9)$ \\
\hline & $20-29$ & $82(67.2)$ & $68(55.7)$ & $122(60.6)$ \\
\hline & $30-39$ & $12(66.7)$ & $6(33.3)$ & $18(9)$ \\
\hline & $40-49$ & $13(92.9)$ & $9(64.3)$ & $14(7)$ \\
\hline & $50-59$ & $12(92.3)$ & $5(38.5)$ & $13(6.4)$ \\
\hline & $\geq 60$ & $13(92.9)$ & $5(35.7)$ & $14(7)$ \\
\hline \multirow{2}{*}{ Residence } & Urban & $101(71.6)$ & $76(53.9)$ & $141(70.1)$ \\
\hline & Rural & $42(70)$ & $30(50)$ & $60(29.9)$ \\
\hline \multirow{6}{*}{ Occupation } & Farmer & $30(78.9)$ & $19(50)$ & $38(18.9)$ \\
\hline & Student & $73(70.2)$ & $64(61.5)$ & $104(51.7)$ \\
\hline & Government & $14(63.6)$ & $8(36.4)$ & $22(11)$ \\
\hline & House wife & $17(73.9)$ & $9(39.1)$ & $23(11.4)$ \\
\hline & Merchant & $7(87.5)$ & $4(50)$ & $8(4)$ \\
\hline & No jobs & $2(33.3)$ & $2(33.3)$ & $6(3)$ \\
\hline \multirow{4}{*}{ Education } & Illiterate & $40(80)$ & $24(48)$ & $50(24.9)$ \\
\hline & Primary & $12(63.2)$ & $8(42.1)$ & $19(9.5)$ \\
\hline & Secondary & $15(62.5)$ & $10(41.7)$ & $24(11.9)$ \\
\hline & College & $76(70.4)$ & $64(49.3)$ & $108(53.7)$ \\
\hline \multirow{2}{*}{ Marital status } & Married & $56(81.2)^{* *}$ & $34(49.3)$ & $69(34.3)$ \\
\hline & Single & $87(65.9)$ & $72(54.5)$ & $132(65.7)$ \\
\hline \multirow{3}{*}{ Number of siblings } & 0 & $94(67.1)$ & $80(57.1)$ & $140(69.7)$ \\
\hline & $1-4$ & $29(76.3)$ & $15(39.5)$ & $38(18.9)$ \\
\hline & $5-10$ & $20(87)$ & $11(47.8)$ & $23(11.4)$ \\
\hline
\end{tabular}

$N=$ number $\mathrm{Ag}=$ antigen; $\mathrm{Ab}=$ antibody. ${ }^{*} P$ value $=0.044 ;{ }^{* *} P$ value $=0.016$.

TABle 2: Prevalence of $H$. pylori infection among the dyspeptic patients attending the University of Gondar Hospital Outpatient Department, $N=201$.

\begin{tabular}{lcccc}
\hline \multirow{2}{*}{ Serologic tests } & \multicolumn{4}{c}{ Prevalence of $H$. pylori } \\
& $N$ & Percent (\%) & SE & 95\% CI \\
\hline dBest H. pylori Ab rapid test & 143 & 71.1 & 3.2 & $64.2-77.6$ \\
SD BIOLINE H. pylori Ag test & 75 & 37.3 & 3.5 & $30.3-44.3$ \\
\hline
\end{tabular}

$N=$ number; $\mathrm{SE}=$ standard error; $\mathrm{CI}=$ confidence interval; $\mathrm{Ag}=$ antigen; $\mathrm{Ab}=$ Antibody.

the $\mathrm{Ab}$ and $\mathrm{Ag}$ tests) than others, and meanwhile H. pylori seropositivity, using the dBest $H$. pylori Disk tests, is significantly associated with the age groups $<10$ years $(P$ value $=$ $0.044)$ and married patients $(P$ value $=0.016)($ Table 1$)$.

3.3. H. pylori Infection across Clinical Parameters and Associated Risk Factors. Clinically, the patients with heartburn, abdominal fullness, and belching had come up with positive for the H. pylori tests, and likewise, belching is significantly associated $(P=0.038)$, in logistic regression, with the antibody test. In those patients with $H$. pylori (a positive result with either $\mathrm{a} \mathrm{Ab}$ or $\mathrm{Ag}$ test), drinking water from well sources had 2.23 times risk of getting $H$. pylori infection $(P=0.017)$, and drinking coffee $(1.51(0.79-2.96, P=0.025)$ and chat chewing $(1.78(1.02-3.46, P=0.008)$ are the most common risk factors (Tables 3 and 4 ).

\section{Discussion}

A recent study demonstrated that $65.3 \%$ of the patients were positive for $H$. pylori IgG using the immunochromatographic method [13]. This shows that the current prevalence of $H$. pylori infection based on antibodies is much lower. The current $37.3 \%$ magnitude of $H$. pylori, using the SD BIOLINE H. pylori Ag test, is lower than a $52.3 \%$ and $53 \%$ of report from Ethiopia $[18,19]$ and studies from African and Asian countries [20-22]. The variation for these findings might be the difference in the socioeconomic factors, exposure for risk factors, study settings, and essentially the variability in the diagnostic methods.

The present study revealed that $H$. pylori seropositivity has been associated with age. In developing nations, where the majority of children are infected before the age of 10 , the prevalence in adults peaks at more than $80 \%$ before age 50 [23-25]. While in developed countries, evidence of infection in children is unusual but becomes more common later on adulthood. In this study, the increment in serological positivity of $H$. pylori is seen starting from children through adulthood which reaches the peak on 18-30 age groups (68 $(55.7 \%))$, but cases are becoming lower as the age gets older and older. Within any age group, infection appears to be more common in blacks and Hispanics compared to the white population; these differences are probably in part related to socioeconomic factors [26, 27]. 
TABle 3: Prevalence of $H$. pylori infection among the dyspeptic patients across risk factors at the University of Gondar Hospital Outpatient Department, $N=201$.

\begin{tabular}{|c|c|c|c|c|c|c|}
\hline \multicolumn{2}{|l|}{ Risk factors } & \multirow{2}{*}{$\begin{array}{c}\text { Positive for the Ab test, } N(\%) \\
111(69.4)\end{array}$} & \multirow{2}{*}{$\begin{array}{c}\text { Positive for the Ag test, } N(\%) \\
86(53.8)\end{array}$} & \multirow{2}{*}{$\frac{\text { Total, } N(\%)}{160(79.6)}$} & \multirow[t]{2}{*}{$\begin{array}{l}\text { Multivariate } \\
\text { OR }(95 \% \text { CI }) \\
\end{array}$} & $P$ value \\
\hline \multirow{3}{*}{ Water source } & Pipeline & & & & & \\
\hline & River & $27(77.1)$ & $15(42.9)$ & $35(17.4)$ & $2.23(1.26-4.46)$ & 0.017 \\
\hline & Well & $5(83.3)$ & $5(83.3)$ & $6(3)$ & & \\
\hline \multicolumn{2}{|c|}{$\begin{array}{l}\text { Washing hands } \\
\text { with soap }\end{array}$} & $87(73.1)$ & $63(52.9)$ & $119(59.2)$ & $1.04(0.39-2.9)$ & 0.743 \\
\hline \multicolumn{2}{|c|}{ Using toilet } & $69(73.4)$ & $49(52.1)$ & $94(46.8)$ & $1.80(0.62-6.48)$ & 0.496 \\
\hline \multicolumn{2}{|c|}{ Drinking alcohol } & $40(65.6)$ & $34(55.7)$ & $61(30.3)$ & $1.02(0.48-2.9)$ & 0.949 \\
\hline \multicolumn{2}{|c|}{ Drinking coffee } & $69(74.2)$ & $51(54.8)$ & $93(46.3)$ & $1.51(0.79-2.96)$ & 0.025 \\
\hline \multicolumn{2}{|c|}{ Chat chewing } & $4(80)$ & $4(80)$ & $5(2.5)$ & $1.78(1.02-3.46)$ & 0.008 \\
\hline
\end{tabular}

Table 4: Prevalence of $H$. pylori infection among the dyspeptic patients across clinical parameters at the University of Gondar Hospital Outpatient Department, $N=201$.

\begin{tabular}{lccc}
\hline Clinical parameters & Positive for the Ab test, $N(\%)$ & Positive for the Ag test, $N(\%)$ & Total, $N(\%)$ \\
\hline Heartburn & $139(70.6)$ & $104(47.2)$ & $197(98)$ \\
Epigastric pain & $139(70.9)$ & $103(52.6)$ & $196(97.5)$ \\
Abdominal fullness & $133(70.4)$ & $101(53.4)$ & $189(94)$ \\
Vomiting & $51(72.9)$ & $41(58.6)$ & $70(34.8)$ \\
Nausea & $106(71.1)$ & $83(55.7)$ & $149(74.1)$ \\
Belching & $110(71.4)$ & $27(48.7)^{*}$ & $154(76.6)$ \\
Melena & $43(71.7)$ & $12(75)$ & $60(29.9)$ \\
Bloody vomiting & $14(87.5)$ & $16(8)$ \\
\hline
\end{tabular}

$N=$ number; $\mathrm{Ab}=$ antibody; $\mathrm{Ag}=$ antigen. ${ }^{*} P$ value $=0.038$.

The increased prevalence of infection with age was initially thought to represent a continuing rate of bacterial acquisition throughout one's lifetime. However, epidemiologic evidence now indicates most infections are acquired during childhood even in developed countries [24, 28]. Most infections were acquired before five years of age with a declining incidence thereafter in one report from Ireland [29]. Thus, the frequency of $H$. pylori infection for any age group in any locality reflects that particular cohort's rate of bacterial acquisition during childhood years [28]. The organisms can be cultured from vomitus or diarrheal stools suggesting the potential for transmission among family members during periods of illness [30, 31].

The risk of acquiring $H$. pylori infection is related to the socioeconomic status and living conditions early in life. Factors such as density of housing, overcrowding, number of siblings, sharing a bed, and lack of running water have all been linked to a higher acquisition rate of $H$. pylori infection [32-34]. Our study proved that risk factors for acquiring $H$. pylori infection are most prevalent in the patients with $H$. pylori infection. Moreover, studies in the developing countries continue to show that childhood hygiene practices, and family education determines the prevalence of $H$. pylori infection [35]. In this study, illiterate individual accounts the majority (40/143 were positive for $H$. pylori Ab, and 24/106 were positive for $H$. pylori Ag tests) of $H$. pylori cases next to those who visited college. The association of $H$. pylori infection with the level of education, income, and race/ethnicity is not unique to $H$. pylori, since similar associations have been described with other chronic infections including cytomegalovirus, herpes simplex virus-1, and hepatitis B [36]. Studies indicated that declination of $H$. pylori infection has been attributed to economic progress and improvement in sanitation [37]. This study revealed that most (101/143 (antibody); 76/106 (antigen)) H. pylori positive cases are from the urban areas indicating that urbanization accompanied with poor sanitation.

The route by which infection occurs remains unknown, but multiple ways of transmission are reported [38, 39]. Person-to-person transmission of $H$. pylori through either fecal/oral or oral/oral seems most likely [31, 39]. Humans appear to be the major reservoir of infection; however, $H$. pylorus has been isolated from primates in captivity and from domestic cats $[40,41]$. One report described the identification of H. pylori in milk and gastric tissue of sheep suggesting that sheep may be a natural host for the organism [42]. This may explain the higher infection rate that has been observed among shepherds compared to their siblings [43]. Similarly in our study, form the total $H$. pylori cases, farmers accounted the second highest proportion showing that close contact with domestic cattle may potentially result $H$. pylori transmission.

In addition to fecal/oral transmission of bacteria, contaminated water supplies in developing countries may serve as an environmental source of bacteria. In this study, majority (111/143 (antibody), 86/106 (antigen)) of H. pylori positive individuals use water sources from pipeline. The organism remains viable in water for several days and, using the polymerase chain reaction techniques, evidence of $H$. pylori can be found in most samples of municipal water from the endemic areas of infection [44-46]. Children who regularly swim in rivers, streams, and pools drink stream water, 
or eat uncooked vegetables are more likely to be infected [47]. H. pylori have been cultured from diarrheal stools of children in Gambia, West Africa, where almost all inhabitants are infected by five years of age [48].

Intrafamilial clustering of infection further supports person-to-person transmission. Infected individuals are more likely to have infected spouses and children than uninfected individuals $[34,49]$. A study of children in Columbia found that the risk of infection correlated directly with the number of children aged 2 to 9 in the household, while younger children were more likely to be infected if older siblings were also infected [50]. Isolation of genetically identical strains of $H$. pylori from multiple family members [51] and custodial patients in the same institution [52] and further studies support transmission among persons sharing the same living environment. In addition to the familial type of transmission that occurs in developed and other nations, horizontal transmission between persons who do not belong to a core family also appears to take place in countries where the prevalence of infection is high [49]. As revealed by studies conducted on Ethiopia and Thailand [14, 53, 54], $H$. pylori infection is higher in married individuals demonstrating that cluster living environment has an impact on $\mathrm{H}$. pylori transmission.

At last, it should be considered that the dyspeptic patients, other than the present serum antibody and stool antigen tests, did not undergo further confirmatory tests (endoscopy with biopsy for the histology culture and/or the very least urea breath test) due to economic constraints.

\section{Conclusion}

The present study discovered considerable magnitude of $H$. pylori in the study area. H. pylori infection is frequent in individuals drinking water from well sources, and thus, poor sanitation and unhygienic water supply are contributing factors. Policies aiming at improving the socioeconomic status will reduce potential sources of infection, transmission, and ultimately the prevalence and incidence of $H$. pylori infection.

\section{Abbreviations}

$\begin{array}{ll}\text { Ab: } & \text { Antibody } \\ \text { Ag: } & \text { Antigen } \\ \text { IgG: } & \text { Immunoglobulin G } \\ \text { IgM: } & \text { Immunoglobulin M } \\ \text { IRB: } & \text { Institutional Review Board } \\ \text { SD: } & \text { Standard deviation } \\ \text { SPSS: } & \text { Statistical Package for Social Sciences } \\ \text { UOG: } & \text { University of Gondar Hospital. }\end{array}$

\section{Data Availability}

The dataset supporting the conclusions of this article is included within the article.

\section{Ethical Approval}

This project was ethically cleared by the Institutional Review Board (IRB) of the University of Gondar. Participation was voluntary, and informed verbal consent was taken from all adult participants and from the next of kin, caretakers, or guardians on behalf of the minors/children before inclusion to the study. Initially, the participants were briefly explained about the objectives of the study, risks, and benefits of the procedures and on voluntary participation and the right to withdraw at any stage of the study using their local language. Participants were then asked if they understood what has been explained to them. If and only if they understand the facts, implications, and future consequences of their action on themselves or their children, they would like to be part of the study. Written consent was not acquired because all the participants were recruited from the outpatient department laboratory of the Gondar University Hospital where all the participant patients were sent to undergo the $H$. pylori antibody test. The additional stool antigen test was a noninvasive procedure with minimal or no risk associated with it. Besides, the patients were benefited from the stool antigen test as it added further information on whether to commence eradication therapy by the attending physician. The result from the antibody test was collected from the laboratory record book. Official permission was also obtained from the University of Gondar Hospital before access to the record book and the conduct of the study. Therefore, considering all these facts, only the verbal agreement was acquired to be included in the study. The IRB has also evaluated the consent procedure and cleared it as sufficient. Participants who were diagnosed as positive to the H. pylori stool antigen test were immediately linked to the medical outpatient department of the University of Gondar Hospital for appropriate treatment and follow-up.

\section{Conflicts of Interest}

The authors declare that they have no conflicts of interest with regard to the present study.

\section{Authors' Contributions}

$\mathrm{MN}, \mathrm{HWB}$, and DG conceived the study concept and designed the study. MN and DG carried out data collection and laboratory analysis. MN, HWB, and DG supervised the data collection and laboratory analysis. MN, HWB, and DG analyzed the data and prepared the first manuscript draft. MN and DG reviewed the draft. All authors read and approved the final manuscript. All the authors are currently working at the University of Gondar.

\section{Acknowledgments}

Our gratitude goes to the technical staffs, the University of Gondar Hospital, and the staff for the unreserved support during the study and all the study participants. 


\section{References}

[1] J. G. Kusters, A. H. M. Van Vliet, and E. J. Kuipers, "Pathogenesis of Helicobacter pylori infection," Clinical Microbiology Reviews, vol. 19, no. 3, pp. 449-490, 2006.

[2] M. Safavi, R. Sabourian, and A. Foroumadi, "Treatment of Helicobacter pylori infection: current and future insights," World Journal of Clinical Cases, vol. 4, no. 1, pp. 5-19, 2016.

[3] B. A. Salih, "Helicobacter pylori infection in developing countries: the burden for how long?," Saudi Journal of Gastroenterology, vol. 15, no. 3, pp. 201-207, 2009.

[4] R. M. Patrick, S. R. Kenn, and A. P. Michel, Medical Microbiology, Elsevier, New York, NY, USA, 5th edition, 2005.

[5] Y. G. David, Y. C. Lee, and M. S. Wu, "Rational Helicobacter pylori therapy: evidence-based medicine rather than medicine-based evidence," Clinical Gastroenterology and Hepatology, vol. 12, no. 2, pp. 177.e3-186.e3, 2014.

[6] R. S. Mhaskar, I. Ricardo, A. Azliyati et al., "Assessment of risk factors of Helicobacter pylori infection and peptic ulcer disease," Journal of Global Infectious Diseases, vol. 5, no. 2, pp. 60-67, 2013.

[7] D. Asrat, I. Nilsson, Y. Mengistu et al., "Prevalence of Helicobacter pylori infection among adult dyspeptic patients in Ethiopia," Annals of Tropical Medicine \& Parasitology, vol. 98, no. 2, pp. 181-189, 2004.

[8] T. N. A. Archampong, R. H. Asmah, E. K. Wiredu, R. K. Gyasi, K. N. Nkrumah, and K. Rajakumar, "Epidemiology of Helicobacter pylori infection in dyspeptic Ghanian patients," Pan African Medical Journal, vol. 20, p. 178, 2015.

[9] T. Fasciana, C. Calà, C. Bonura et al., "Resistance to clarithromycin and genotypes in Helicobacter pylori strains isolated in Sicily," Journal of Medical Microbiology, vol. 64, no. 11, pp. 1408-1414, 2015.

[10] J. K. Y. Hooi, W. Y. Lai, W. K. Ng et al., "Global prevalence of Helicobacter pylori infection: systematic review and metaanalysis," Gastroenterology, vol. 153, no. 2, pp. 420-429, 2017.

[11] K. Desta, D. Asrat, and F. Derbie, "Seroprevalence of Helicobacter pylori infection among healthy blood donors in Addis Ababa, Ethiopia," Ethiopian Journal of Health Sciences, vol. 12, pp. 109-115, 2002.

[12] T. Tesfahun, M. Yohannes, D. Kassu, and A. Daniel, "Seroprevalence of Helicobacter pylori infection in and its relationship with $\mathrm{ABO}$ blood groups," Ethiopian Journal of Health Development, vol. 19, no. 1, pp. 55-59, 2005.

[13] M. Biniam, M. Beyene, and D. Mulat, "Seroprevalence and trend of Helicobacter pylori infection in Gondar University hospital among dyspeptic patients, Gondar, North West Ethiopia," BMC Research Notes, vol. 6, no. 1, p. 346, 2013.

[14] M. Feleke, K. Afework, M. Getahun et al., "Seroprevalence of Helicobacter pylori in dyspeptic patients and its relationship with HIV infection, ABO blood groups and life style in a university hospital, Northwest Ethiopia," World Journal of Gastroenterology, vol. 12, no. 12, pp. 1957-1961, 2006.

[15] Y. Niv and T. Rokkas, "Recent advances in Helicobacter pylori eradication," Annals of Gastroenterology, vol. 28, no. 4, pp. 415-416, 2015.

[16] A. S. Doffou, K. A. Attia, M. F. Yao Bathaix et al., "The Helicobacter pylori eradication rate in a high prevalence area (West Africa): three triple therapy comparative study," Open Journal of Gastroenterology, vol. 5, no. 12, pp. 200-206, 2015.

[17] M. Negash, A. Kassu, B. Amare, G. Yismaw, and B. Moges, "Evaluation of SD BIOLINE H. pylori Ag rapid test against double ELISA with SD H. pylori Ag ELISA and EZ-STEP
H. pylori Ag ELISA tests," BMC Clinical Pathology, vol. 18, no. 1 , p. $4,2018$.

[18] K. Dargaze, G. Baye, A. Agersew, and A. Zelalem, "Helicobacter pylori infection and its association with anemia among adult dyspeptic patients attending Butajira Hospital, Ethiopia," BMC Infectious Diseases, vol. 14, no. 1, p. 656, 2014.

[19] G. Taddesse, A. Habteselassie, K. Desta, S. Esayas, and A. Bane, "Association of dyspepsia symptoms and Helicobacter pylori infections in private higher clinic, Addis Ababa, Ethiopia," Ethiopian Medical Journal, vol. 49, pp. 109-116, 2011.

[20] H. Shmuely, S. Obure, J. D. Passaro et al., "Dyspepsia symptoms and Helicobacter pylori infection, Nakuru, Kenya," Emerging Infectious Diseases, vol. 9, no. 9, pp. 1103-1107, 2003.

[21] B. V. Oti, R. G. Pennap, O. Dennis, S. A. Ajegena, and P. M. Adoga, "Prevalence and predictors of Helicobacter pylori infection among patients attending a healthcare facility in North-Central Nigeria," Asian Pacific Journal of Tropical Disease, vol. 7, no. 6, pp. 352-355, 2017.

[22] L. Shokrzadeh, K. Baghaei, Y. Yamaoka et al., "Prevalence of Helicobacter pylori infection in dyspeptic patients in Iran," Gastroenterology Insights, vol. 4, no. 1, p. 8, 2012.

[23] M. Selgrad, A. Kandulski, and P. Malfertheiner, "Dyspepsia and Helicobacter pylori," Digestive Disease, vol. 26, no. 3, pp. 210-214, 2008.

[24] M. S. Pearce, D. I. Campbell, K. D. Mann, L. Parker, and J. E. Thomas, "Deprivation, timing of preschool infections and H. pylori seropositivity at age 49-51 years: the Newcastle thousand families' birth cohort," BMC Infectious Diseases, vol. 13, no. 1, p. 422, 2013.

[25] W. Jafri, J. Yakoob, S. Abid, S. Siddiqui, S. Awan, and S. Q. Nizami, "Helicobacter pylori infection in children: population-based age-specific prevalence and risk factors in a developing country," Acta Paediatrica, vol. 99, no. 2, pp. 279-282, 2010.

[26] U. C. Ghoshal, R. Chaturvedi, and P. Correa, "The enigma of Helicobacter pylori infection and gastric cancer," Indian Journal of Gastroenterology, vol. 29, no. 3, pp. 95-100, 2010.

[27] A. C. Hernando-Harder, N. Booken, S. Goerdt, M. V. Singer, and H. Harder, "Helicobacter pylori infection and dermatologic diseases," European Journal of Dermatology, vol. 19, no. 5, pp. 431-444, 2009.

[28] E. Chak, G. W. Rutherford, and C. Steinmaus, "The role of breast-feeding in the prevention of Helicobacter pylori infection: a systematic review," Clinical Infectious Diseases, vol. 48, no. 4, pp. 430-437, 2009.

[29] M. Rowland, L. Daly, M. Vaughan, A. Higgins, B. Bourke, and B. Drumm, "Age-specific incidence of Helicobacter pylori," Gastroenterology, vol. 130, no. 1, pp. 65-72, 2006.

[30] A. Vega, H. Silva, and T. Cortiñas, "Evaluation of a serum-free transport medium supplemented with cyanobacterial extract, for the optimal survival of Helicobacter pylori from biopsy samples and strains," European Journal of Clinical Microbiology \& Infectious Diseases, vol. 31, no. 2, pp. 135-139, 2012.

[31] S. Perry, M. De La Luz Sanchez, S. Yang et al., "Gastroenteritis and transmission of Helicobacter pylori infection in households," Emerging Infectious Diseases, vol. 12, no. 11, pp. 1701-1708, 2006.

[32] S. I. Yokota, M. Konno, S. I. Fujiwara et al., "Intrafamilial, preferentially mother-to-child and intraspousal, Helicobacter pylori infection in Japan determined by mutilocus sequence typing and random amplified polymorphic DNA fingerprinting," Helicobacter, vol. 20, no. 5, pp. 334-342, 2015. 
[33] R. Shi, S. Xu, H. Zhang et al., "Prevalence and risk factors for Helicobacter pylori infection in Chinese populations," Helicobacter, vol. 13, no. 2, pp. 157-165, 2008.

[34] M. Kivi, A. L. Johansson, M. Reilly, and Y. Tindberg, "Helicobacter pylori status in family members as risk factors for infection in children," Epidemiology and Infection, vol. 133, no. 4 , pp. $645-652,2005$.

[35] M. Nouraie, S. Latifi-Navid, H. Rezvan et al., "Childhood hygienic practice and family education status determine the prevalence of Helicobacter pylori infection in Iran," Helicobacter, vol. 14, no. 1, pp. 40-46, 2009.

[36] A. Zajacova, J. B. Dowd, and A. E. Aiello, "Socioeconomic and race/ethnic patterns in persistent infection burden among $U$. S. adults," Journals of Gerontology Series A: Biological Sciences and Medical Sciences, vol. 64A, no. 2, pp. 272-279, 2009.

[37] F. Rasheed, T. Ahmad, and R. Bilal, "Prevalence and risk factors of Helicobacter pylori infection among Pakistani population," Pakistan Journal of Medical Sciences, vol. 28, no. 4, pp. 661-665, 2012.

[38] C. Dube, T. C. Nkosi, A. M. Clarke, N. Mkwetshana, E. Green, and R. N. Ndip, "Helicobacter pylori in an asymptomatic population of eastern Cape Province, South Africa: public health implication," Reviews on Environmental Health, vol. 24, no. 3, pp. 249-255, 2009.

[39] B. Stanström, A. Mendis, and B. Marshall, "Helicobacter pylori the latest in diagnosis and treatment," Australian Family Physician, vol. 37, no. 8, pp. 608-612, 2008.

[40] A. A. Mohamed and A. H. El-Gohari, "Epidemiological aspects of Helicobacter pylori infections as an emergence zoonotic disease: animal reservoirs and public health implications (a review article)," in Proceedings of 7th International Scientific Conference, pp. 17-25, Mansoura, Egypt, 2012.

[41] M. Tabatabaei, "Application of molecular and central cultural methods for identification of Helicobacter spp in different animal sources," Global Veterinaria, vol. 8, pp. 292-297, 2012.

[42] M. P. Dore, A. R. Sepulveda, H. El-Zimaity et al., "Isolation of Helicobacter pylori from sheep-implications for transmission to humans," American Journal of Gastroenterology, vol. 96, no. 5, pp. 1396-1401, 2001.

[43] M. P. Dore, M. Bilotta, D. Vaira et al., "High prevalence of Helicobacter pylori infection in shepherds," Digestive Diseases and Sciences, vol. 44, no. 6, pp. 1161-1164, 1999.

[44] N. C. Quaglia, A. Dambrosio, G. Normanno et al., "High occurrence of Helicobacter pylori in raw goat, sheep and cow milk inferred by glmM gene: a risk of food-borne infection?," International Journal of Food Microbiology, vol. 124, no. 1, pp. 43-47, 2008.

[45] N. R. Bellack, M. W. Koehoorn, Y. C. MacNab, and M. G. Morshed, “A conceptual model of water's role as a reservoir in Helicobacter pylori transmission: a review of the evidence," Epidemiology and Infection, vol. 134, no. 3, p. 439, 2006.

[46] N. Queralt, R. Bartolomé, and R. Araujo, "Detection of Helicobacter pylori DNA in human faeces and water with different levels of faecal pollution in the north-east of Spain," Journal of Applied Microbiology, vol. 98, no. 4, pp. 889-895, 2005.

[47] T. L. Cover and M. J. Blaser, "Helicobacter pylori in health and disease," Gastroenterology, vol. 136, no. 6, pp. 1863-1873, 2009.

[48] O. Secka, Y. Moodley, M. Antonio et al., "Population genetic analyses of Helicobacter pylori isolates from Gambian adults and children," PLoS One, vol. 9, no. 10, Article ID e109466, 2014.
[49] S. Schwarz, G. Morelli, B. Kusecek et al., "Horizontal versus familial transmission of Helicobacter pylori," PLoS Pathogens, vol. 4, no. 10, article e1000180, 2008.

[50] K. J. Goodman and P. Correa, "Transmission of Helicobacter pylori among siblings," The Lancet, vol. 355, no. 9201, pp. 358-361, 2000.

[51] T. Falsafi, N. Sotoudeh, M. M. Feizabadi, and F. Mahjoub, "Analysis of genomic diversity among Helicobacter pylori strains isolated from iranian children by pulsed field gel electrophoresis," Iranian Journal of Pediatrics, vol. 24, no. 6, pp. 703-709, 2014.

[52] B. Linz, C. R. R. Vololonantenainab, A. Seck et al., "Population genetic structure and isolation by distance of Helicobacter pylori in Senegal and Madagascar," PLoS One, vol. 9, no. 1, Article ID e87355, 2014.

[53] H. L. Chen, M. J. Chen, S. C. Shih, H. Y. Wang, I. T. Lin, and M. J. Bair, "Socioeconomic status, personal habits, and prevalence of Helicobacter pylori infection in the inhabitants of Lanyu," Journal of the Formosan Medical Association, vol. 113, no. 5, pp. 278-283, 2014.

[54] T. Uchida, M. Miftahussurur, R. Pittayanon et al., "Helicobacter pylori infection in Thailand: a nationwide study of the CagA phenotype," PLoS One, vol. 10, no. 9, Article ID e0136775, 2015. 


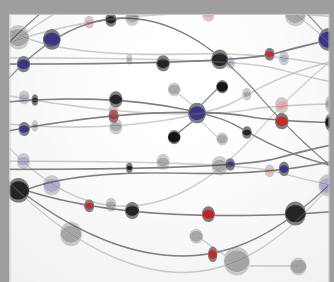

The Scientific World Journal
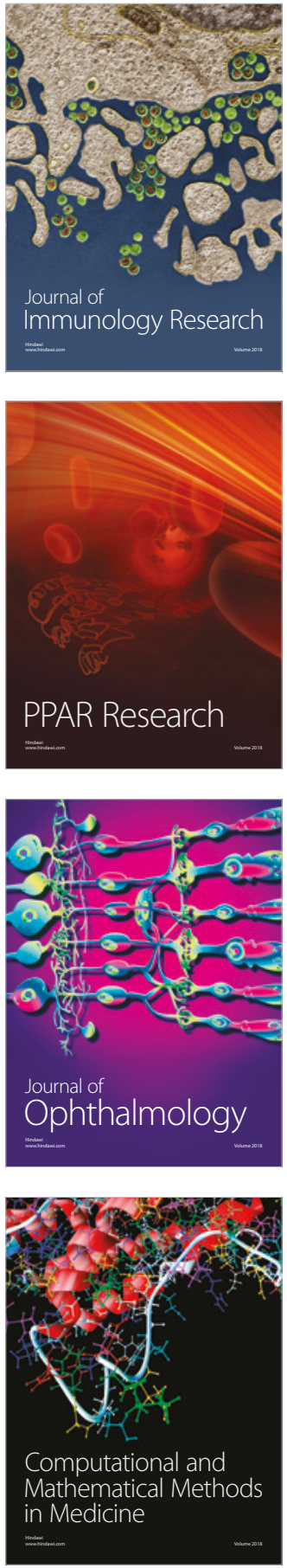

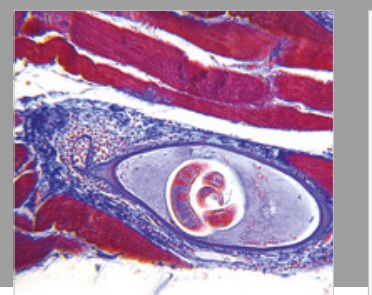

Gastroenterology Research and Practice

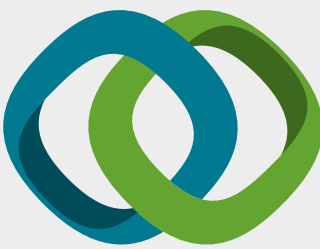

\section{Hindawi}

Submit your manuscripts at

www.hindawi.com
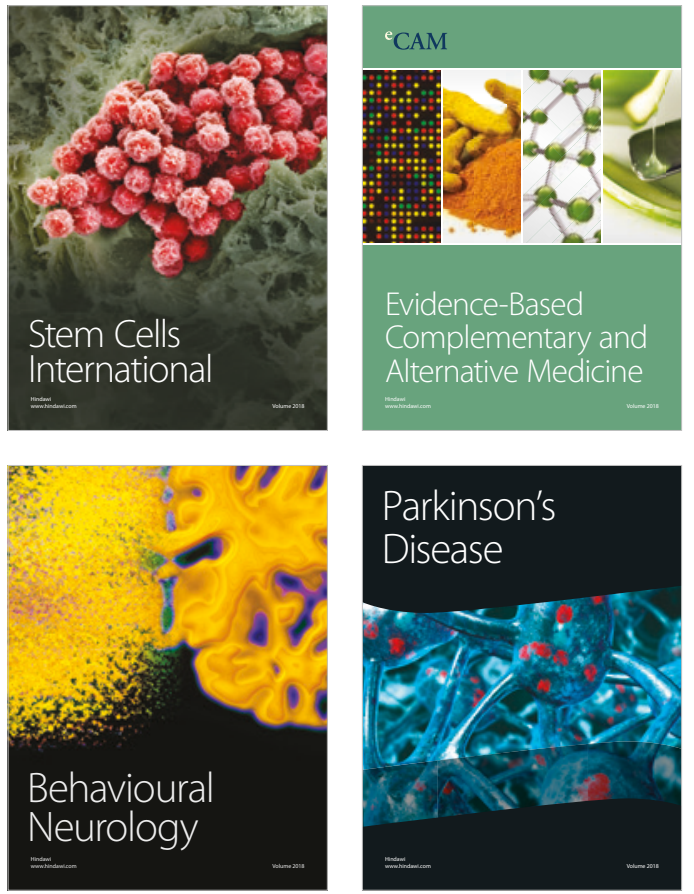

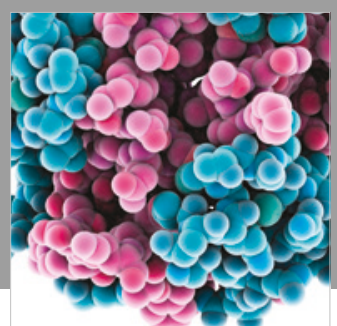

ournal of

Diabetes Research

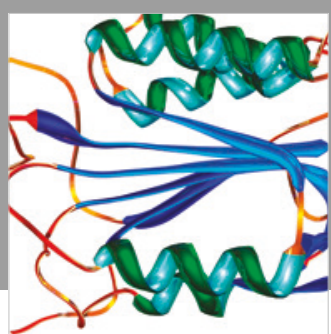

Disease Markers
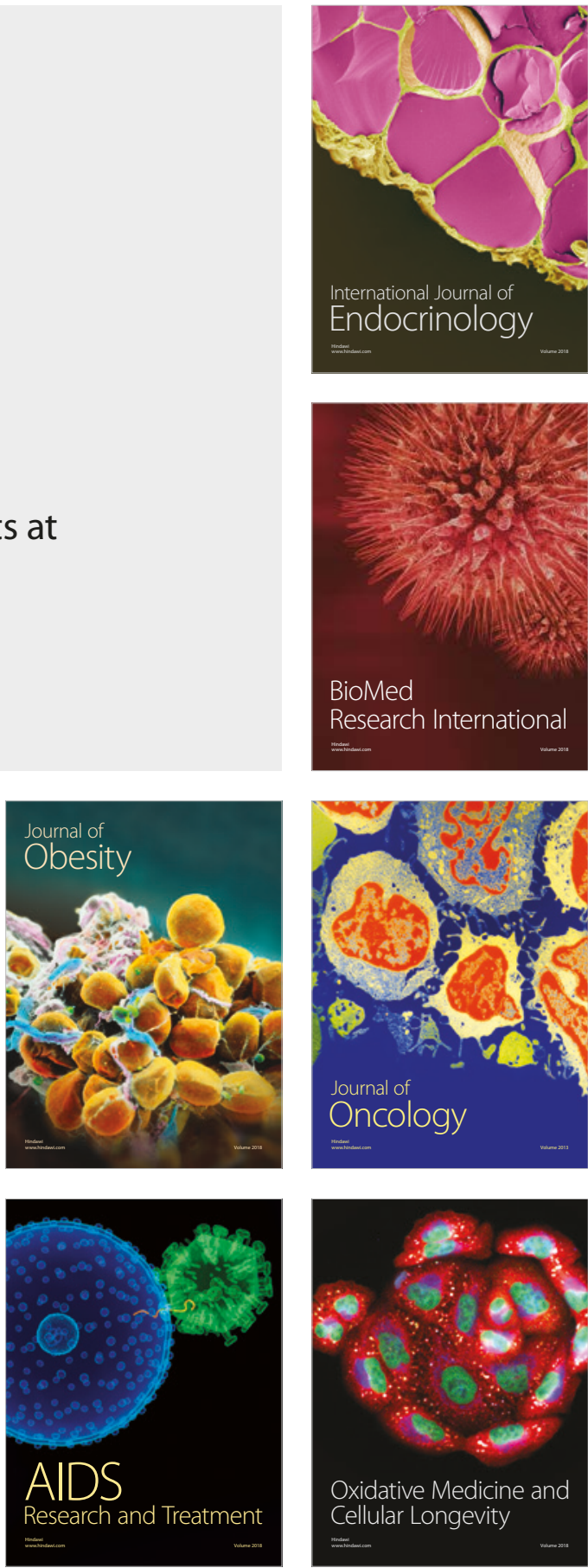